\title{
Essential Oils as Treatment Strategy for Alzheimer's Disease: Current and Future Perspectives
}

\author{
Authors \\ Anju Benny, Jaya Thomas
}

\begin{abstract}
Affiliation
Department of Pharmacology, Amrita School of Pharmacy, Amrita University, Amrita Vishwa Vidyapeetham, AIMS Health Sciences Campus, Kochi, India
\end{abstract}

Key words

Alzheimer's disease, essential oils, antioxidant, anti-acetylcholinesterase, amyloid $\beta$ protein

received May 28, 2018

revised September 29, 2018

accepted October 10, 2018

Bibliography

DOI https://doi.org/10.1055/a-0758-0188

Published online October 25, 2018 | Planta Med 2019; 85:

239-248 @ Georg Thieme Verlag KG Stuttgart · New York I ISSN 0032-0943

Correspondence

Dr. Jaya Thomas

Department of Pharmacology, Amrita School of Pharmacy, Amrita Institute of Medical Sciences

Edappally, Kochi, Kerala, India, 682041

Phone: + 918860151089 , Fax: + 9104842802020

jayamarythomas@gmail.com

\section{ABSTRACT}

Alzheimer's disease is a multifarious neurodegenerative disease that causes cognitive impairment and gradual memory loss. Several hypotheses have been put forward to postulate its pathophysiology. Currently, few drugs are available for the management of Alzheimer's disease and the treatment provides only symptomatic relief. Our aim is to review the relevant in vitro, in vivo, and clinical studies focused toward the potential uses of essential oils in the treatment of Alzheimer's disease. Scientific databases such as PubMed, ScienceDirect, Scopus, and Google Scholar from April 1998 to June 2018 were explored to collect data. We have conducted wide search on various essential oils used in different models of Alzheimer's disease. Out of 55 essential oils identified for Alzheimer's intervention, 28 have been included in the present review. A short description of in vivo studies of 13 essential oils together with clinical trial data of Salvia officinalis, Salvia lavandulifolia, Melissa officinalis, Lavandula angustifolia, and Rosmarinus officinalis have been highlighted. In vitro studies of remaining essential oils that possess antioxidant and anticholinesterase potential are also mentioned. Our literary survey revealed encouraging results regarding the various essential oils being studied in preclinical and clinical studies of Alzheimer's disease with significant effects in modulating the pathology through anti-amyloid, antioxidants, anticholinesterase, and memory-enhancement activity.

\section{Introduction}

Alzheimer's disease (AD) is a multifarious neurodegenerative disease that causes cognitive impairment and gradual memory loss. Senile plaques and neurofibrillary tangles (NFTs) comprised of amyloid $\beta(A \beta)$ peptides and hyper-phosphorylated tau proteins, respectively, are the classic pathological hallmarks of AD [1]. Several hypotheses have been put forward to reveal the pathobiology of the disorder including cholinergic hypothesis, inflammation hypothesis, oxidative stress, mitochondrial cascade hypothesis, and metabolic hypothesis [2,3]. According to the World Health Organization, $A D$ is the most common form of dementia and accounts for about $60-70 \%$ of all dementia cases [4]. There is more prevalence for people aged over 65 y [5]. Epigenetic variations on the genetic material of neurons can result in neurodegenerative disorders and these variations in $A D$ genes change from region to region [6]. Familial Alzheimer's disease (FAD) and sporadic Alzheimer's disease are the 2 specific types of AD [7]. The combined action of environmental and genetic factors might be culpable for the SAD and FAD types [8]. Depending on the age of onset, $A D$ can be further grouped into early onset (EOAD) and late onset (LOAD) [9]. Mutations in some specific genes like amyloid precursor protein (APP), presenilin I, and presenilin II are responsible for EOAD whereas apolipoprotein $\mathrm{E}$ is the only gene identified that causes LOAD [10]. Approximately $5 \%$ of the AD cases is familial early onset type and it develops before $65 \mathrm{y}$ of age, and the remaining $95 \%$ accounts for sporadic late onset type and it develops after 65 y of age $[11,12]$.

The neuropathophysiology of the neurodegeneration in $A D$ is triggered by anomalous deposition of amyloid plaques and NFTs in varied regions of the brain involved in cognition and memory [13]. Amyloid plaques are protein fragments composed of $A \beta$ 


$\begin{array}{ll}\text { ABBREVIATIONS } \\ \text { ABTS } & \text { 2,2-azinobis3-ethylbenzthiazoline-6-sulfonic acid } \\ \text { ACh } & \text { acetylcholine } \\ \text { AChE } & \text { acetylcholinesterase } \\ \text { AD } & \text { Alzheimer's disease } \\ \text { A } \beta & \text { amyloid } \beta \\ \text { APP } & \text { amyloid precursor protein } \\ \text { BChE } & \text { butyrylcholinesterase } \\ \text { DPPH } & 1,1 \text {-diphenyl 2-picrylhydrazyl } \\ \text { EOAD } & \text { early onset Alzheimer's disease } \\ \text { EO } & \text { essential oil } \\ \text { FAD } & \text { familial Alzheimer's disease } \\ \text { ICV } & \text { intracerebroventricular } \\ \text { LD } 50 & \text { lethal dose } 50 \% \\ \text { LOAD } & \text { late onset Alzheimer's disease } \\ \text { MCFA } & \text { medium-chain fatty acid } \\ \text { MWM } & \text { Morris water maze } \\ \text { NFTs } & \text { neurofibrillary tangles } \\ \text { SAD } & \text { sporadic Alzheimer's disease } \\ \text { SHXW } & \text { SuHeXiang Wan } \\ \text { ZM } & \text { Zataria multiflora Boiss } \\ \end{array}$

peptides originated from APP by the synergistic action of enzymes $\beta$-secretase and $\gamma$-secretase [14]. Polymerization of these A $\beta$ peptides results into insoluble filaments that build up in the walls of cerebral blood vessels and configure senile plaques. Microglial activation, reactive astrocytosis, cytokine release, and neuro-inflammation also occur in accordance with the formation of amyloid plaques [15]. NFTs are made up of tau protein found inside the neurons as a bunch of insoluble fibers. Hyperphosphorylation of these tau proteins results in the formation of paired helical filaments and finally forms microscopic tangles that cause cell death [16].

Out of all above pathogenetic pathways, the mechanisms of essential oils (EOs) are associated with cholinergic hypothesis and oxidative stress hypothesis. As stated by cholinergic hypothesis, loss of cholinergic neurotransmission in the cerebral cortex and the destruction of cholinergic neurons in the basal forebrain disturb cognitive function [17]. Depletion of acetylcholine (ACh) level is usually noticed in dementia patients and exploratory studies in animals and humans have also confirmed the role of ACh in learning and memory [18]. Oxidative stress is inevitably linked with various primary $A D$ pathogenesis such as $A \beta$-induced neuronal loss, mitochondria dysfunction, tau protein pathology, and disturbance in metal homeostasis [19]. Senile plaques mediated oxidative imbalance can elevate the levels of lipid peroxidation byproducts, DNA/RNA oxidation, and protein oxidation in several regions of the brain. In addition, oxidative stress causes depletion of brain antioxidants level like uric acid, vitamin $C$ and $E$ and antioxidant enzymes such as catalase, glutathione reductase, superoxide dismutase, etc. [20].

At present, very few drugs are available for the medical care of $A D$ and are directed toward symptomatic relief. The currently available U.S. Food and Drug Administration approved drugs in the market for $A D$ include cholinesterase inhibitors (rivastigmine, galantamine, and donepezil) and N-methyl-D-aspartate receptor antagonist (memantine) [21]. Tacrine has been the first approved drug (1993) as a reversible inhibitor of AChE later on abandoned in 2013 due to its hepatotoxicity, short half-life, and cholinergic side effects [22]. Huperzin A obtained from Huperzia serrata (Thunb.) Trevis (Lycopodiaceae) is a naturally derived AChE inhibitor used in the treatment of memory ailments in China [23].

EOs constitute a blend of enormously complex, volatile, naturally derived compounds that are obtained as secondary metabolites from plants. They are found to be copious in leaves, seeds, flowers, barks, and rhizomes and are commonly obtained through cold pressing, hydro-distillation methods [24]. Its major constituents include monoterpenes hydrocarbon, sesquiterpenes hydrocarbon, oxygenated sesquiterpenes, oxygenated monoterepenes, and esters [25]. A review on therapeutic and pharmaceutical use of EOs related to cardiovascular disease, cancer, antidiabetic, penetration enhancer, antimicrobial, massage therapy, neuroprotective, aromatherapy, and anti-aging effects revealed the immense medicinal benefits of EOs [26]. Dobetsberger and Buchbauer [27] pointed out the analgesic, anxiolytic, anticonvulsive, and anti-AD effects. Recently, the anti-aging and neuroprotective effects of numerous EOs and their involvement in various brain disorders have been outlined [24]. Studies revealed that EOs are classic naturally derived antioxidants and most of them exhibits cholinesterase inhibitory potential and are relevant in $A D$ pathogenesis [28]. - Table 1 shows the list of EOs with respect to their anti-Alzheimer's intervention.

\section{Methods and Results}

Scientific databases such as PubMed, ScienceDirect, Scopus, and Google Scholar from April 1998 to June 2018 were explored to collect data. The keywords searched were Alzheimer's disease, EOs, amyloid hypothesis, NTFs, antioxidants, acetylcholinesterase, and dementia. We have conducted wide search on various EOs used in different models of AD. A total of 540 papers were obtained by scientific search, and 89 papers found to be relevant to the review. Studies of about 55 EOs were identified for Alzheimer's intervention. Twenty-eight EOs were finally included based on the quality of the study of which short descriptions of in vivo studies of 13 EOs together with clinical trial data of Salvia officinalis L., S. officinalis L. ssp. lavandulifolia (vahl) Gams, Melissa officinalis L., Lavandula angustifolia Mill., and Rosmarinus officinalis L. were highlighted. Chemical constituents and medicinal benefits of the EOs, animal models, doses and time of administration, study duration, behavioral parameters, and biochemical and histological assessments were also summarized. In vitro studies of 15 EOs that possess antioxidant and anticholinesterase potential are also mentioned.

\section{Coriandrum sativum}

Coriandrum sativum L. (coriander) of Umbelliferae/Apiaceae family has been reported to have anti-anxiety, anticonvulsive, antioxidative, antispoilage, hypoglycemic, anti-inflammatory, antimutagenic, diuretic, antihypertensive, carminative, hypolipidemic, 
- Table 1 List of EOs with respect to their anti-Alzheimer's intervention.

\begin{tabular}{|c|c|c|c|}
\hline Plant/source & Study design & Results & Reference \\
\hline C. sativum & ICV $A \beta(1-42)$-induced $A D$ in rats & $\begin{array}{l}\text { Reduced oxidative stress induced by } A \beta(1-42) \text { and confer } \\
\text { neuroprotective effects }\end{array}$ & [31] \\
\hline S. aromaticum & ICV colchicine-induced $A D$ in rats & $\begin{array}{l}\text { Reversed memory impairment, restored the levels } \\
\text { of ACh and antioxidants, reduced neuroinflammation and } \\
\text { mitochondrial dysfunction in colchicine treated rats. }\end{array}$ & [33] \\
\hline Z. multifora & ICV $A \beta(25-35)$-induced $A D$ in rats & $\begin{array}{l}\text { Reversed A } \beta \text {-induced learning deficits, exhibited } \\
\text { antioxidant, anti-inflammatory and anti-cholinesterase } \\
\text { activities. }\end{array}$ & [35] \\
\hline \multirow[t]{2}{*}{ SuHeXiang Wan } & Drosophila model of AD & Neuroprotective effects & [39] \\
\hline & ICV A $\beta(1-42)$-induced AD in ICR mice & $\begin{array}{l}\text { Reversed } A \beta(1-42) \text {-mediated memory deficit } \\
\text { Suppressed } A \beta(1-42) \text {-mediated JNK, tau phosphory- } \\
\text { lation, and p38 in the mice hippocampus. }\end{array}$ & {$[40]$} \\
\hline A. nemorosa & $\begin{array}{l}\text { Scopolamine-induced spatial memory impair- } \\
\text { ment in rats }\end{array}$ & Prevented cognitive defects. & {$[42]$} \\
\hline S. officinalis & Single blind trial in healthy volunteers & Enhanced mood and cognitive performance & {$[45]$} \\
\hline \multirow{3}{*}{$\begin{array}{l}\text { S. officinalis ssp. } \\
\text { lavandulifolia (vahl) } \\
\text { Gams }\end{array}$} & Single blind trial in healthy volunteers & No significant effects. & {$[45]$} \\
\hline & $\begin{array}{l}\text { Clinical study in healthy volunteers for mood } \\
\text { and cognition. }\end{array}$ & Enhanced mood and cognition & {$[50]$} \\
\hline & Clinical trial in mild/moderate AD patients & Improved memory and cognition & {$[51]$} \\
\hline \multirow[t]{3}{*}{ M. officinalis } & $\begin{array}{l}\text { Double-blind placebo-controlled trial } \\
\text { in } \mathrm{AD} \text { patients }\end{array}$ & Improved agitation and quality of life indices & {$[54]$} \\
\hline & Clinical trial in AD patients & No significant effects & {$[55]$} \\
\hline & Anti-agitation studies & Anti-agitation effects & {$[56,57]$} \\
\hline J. communis & ICV A $\beta(1-42)$-induced $A D$ in rats & $\begin{array}{l}\text { Reduced memory impairment, antioxidant and } \\
\text { anti-cholinesterase potential }\end{array}$ & {$[59,60]$} \\
\hline \multirow[t]{2}{*}{ C. nucifera } & Prospective study in $A D$ patients & Improved memory status in AD patients. & {$[62]$} \\
\hline & In vitro neurotoxicity study in rat cortical neurons & Neuroprotective effects & {$[63]$} \\
\hline P. peregrina & $\begin{array}{l}\text { Scopolamine-induced memory deficits, } \\
\text { depression, and anxiety in a rat model of } A D\end{array}$ & Hindered depression, anxiety, and memory deficits. & [65] \\
\hline \multirow[t]{2}{*}{ L. angustifolia } & Scopolamine-induced amnesia model in rats & Hindered depression, anxiety, and memory deficits. & {$[69]$} \\
\hline & Clinical trials & Improved mood and cognitive performance. & {$[70,71]$} \\
\hline \multirow[t]{3}{*}{ R. officinalis } & Scopolamine-induced dementia model in mice & Reduced memory impairment. & {$[75]$} \\
\hline & Memory performances in aged and young mice. & Improved memory performances & [76] \\
\hline & Clinical trials & Improved mood and cognitive performances & $\begin{array}{l}{[70,71} \\
76-78]\end{array}$ \\
\hline
\end{tabular}

antispasmodic, and antidepressant effects [29]. The major constituents of its EO include linalool (60-80\%), terpinen-4-ol (3\%), r-cymene (3.5\%), $\gamma$-terpinene (1-8\%), $\alpha$-pinene $(0.2-8.5 \%)$, linalyl acetate $(0-2.7 \%), \alpha$-terpineol $(0.5 \%)$, camphor $(0.9-4.9 \%)$, camphene $(1.4 \%)$, myrcene $(0.2-2.0 \%)$, geranyl acetate $(0.1-4.7 \%)$, and geraniol (1.2-4.6\%) [30]. The effects of EO from dried fruits of $C$. sativum in $A D$ has been studied in an in vivo study by Cioanco et al. [31] AD model was developed in rats by ICV $A \beta(1-42)$ injection and the animals of the test group were made inhale $C$. sativum EO (1\% and $3 \%$ ) daily for $21 \mathrm{~d}$. Cognitive performances were evaluated using radial arm maze and Y-maze tests. $A \beta(1-42)$ treated rats showed notable cognitive dysfunction, which was significantly reversed by EO inhalation. Coriander oil inhalation significantly decreased levels of SOD, LDH, and MDA and increased glutathione peroxidase levels in rat hippocampus. Presence of amyloid deposits were abundant in rats brain induced with ICV $A \beta(1-42)$ and the deposits were less in rats treated with both doses of $C$. sativum EO. Authors concluded that exposure of $C$. sativum $E O$ in $A \beta(1-42)$-induced rats could capably rebuild brain antioxidant status and confer neuroprotective effect possibly due to suppression of oxidative stress caused by $A \beta(1-42)$.

\section{Syzygium aromaticum}

Syzygium aromaticum (L.) Merr. \& L. M. Perry. (clove) is an aromatic flower bud of Myrtaceae family. Clove oil is a mind stimulant used for medical care in anxiety, insomnia, and depression. The active constituents of its EO are eugenol (87.34\%) and smaller amounts of eugenol acetate (5.18\%) and $\beta$-caryophyllene (2.01\%) [32]. The 
neuroprotective potential of clove oil in ICV colchicine-induced memory impairment in rats has been reported in a study by Kumar et al. [33]. Male SD rats were subjected to intraperitoneal injection of minocycline (25 and $50 \mathrm{mg} / \mathrm{kg}$ ), clove oil $(0.05 \mathrm{~mL} / \mathrm{kg}$ and $0.1 \mathrm{~mL} / \mathrm{kg}$ ), and their combinations for $21 \mathrm{~d}$. ICV colchicinetreated rats showed significant cognitive impairment in Morris water maze (MWM) test and showed an increase in AChE activity, oxidative stress, neuro-inflammation, and mitochondrial dysfunction as compared to control group. Treatment with clove oil was found to reverse the memory impairment, restored the levels of ACh and antioxidants, and reduced neuroinflammation and mitochondrial dysfunction in colchicine-treated rats. Authors highlighted that the favorable potential of clove oil in reversing memory impairment and cognitive dysfunction is due to its antioxidative, mitochondrial-restoring, and microglial inhibitory mechanisms.

\section{Zataria multiflora}

Zataria multiflora Boiss (ZM), belonging to Lamiaceae family, is a traditional Iranian herb with anti-inflammatory, antibacterial, antifungal, spasmolytic, antinociceptive, antiprotozoal, antioxidative, and immune stimulant properties. The main constituents of its EO include thymol (40.94\%), carvacrol (22.23\%), p-cymene (7.73\%), linalool (7.92\%), caryophyllene (3.95), and $\gamma$-terpinene [34]. Majlessi et al. [35] mentioned the beneficial effects of EO from the leaves of ZM in ICV A $\beta(25-35)$-induced AD model in rats. Seven days after induction of disease, EO was administered in a dose of 50, 100, and $200 \mu \mathrm{g} / \mathrm{mL}$ (i. p.) 30 min prior to MWM task. $A \beta$ injection in the rat brain remarkably impaired the ability of rats to locate the hidden platform in MWM task. Administration of ZM $E O$ significantly reversed $A \beta$-induced learning deficits. Also, $L D_{50}$ of EO was determined in male NMRI mice and was found to be $1264.9 \mu \mathrm{L} / \mathrm{kg}$. Authors concluded that EO administration remarkably reversed $A \beta(25-35)$-induced cognitive dysfunction in rats due to its antioxidant, anti-inflammatory, and anticholinesterase activities. Further studies are needed to detect the presence of amyloid peptides and neurological alterations and more significant results can be obtained.

\section{SuHeXiang Wan}

SuHeXiang Wan (SHXW) is a conventional Chinese medicinal mixture of about 15 crude herbs including Cyperus rotundus L., Atractylodes macrocephala Koidz., Boswellia sacra Flueck., Bubalus bubalis Linnaeus L. horn powder concentrate, artificial moschus, Santalum album L., Aquilaria sinensis (Lour.) Spreng, Borneolum, Syzygium aromaticum (L.) Merr. \& L. M. Perry, Aucklandia lappa DC., Piper longum L., Terminalia chebula Retz., Liquidambar orientalis Mill., and Styrax tonkinensis Craib ex Hartwich and Cinnabaris [36]. Traditionally, it has been used for seizures, infantile convulsion, CNS depression, and stroke. Analgesic, anticonvulsant, antioxidative, and sedative effects of its EO has been reported [37]. Modified SHXW exhibited neuroprotective effects in drosophila model of $A D[38,39]$. Jeon et al. demonstrated the memory enhancement effect of SHXW EO in an ICR mice model of AD. ICV $A \beta(1-42)$ - or $A \beta(42-1)$-induced mice were subjected to inhalation of $2 \mathrm{~g}$ EO twice daily for $21 \mathrm{~d}$. Behavioral parameters were assessed by step-through passive avoidance and Y-maze tests. The signaling mechanism was examined by measuring the phosphorylation status of the stress stimulated JNK, protein kinases, and p38 in the mice brain. SHXW treatment significantly reversed the $A \beta(1-42)$-mediated memory deficit by suppressing $A \beta(1-42)$-mediated JNK, tau phosphorylation, and p38 in the mice hippocampus. In addition, an in vitro investigation was also performed to examine the inhibitory potential of SHXW EO in $A \beta(1-42)$-incited neurotoxicity in $\mathrm{SH}-\mathrm{SY} 5 Y$ cells. Not reported were any toxic effects on cell viability assays. EO suppressed $A \beta$-induced apoptosis and exhibited antioxidant effect through an upregulation of Nrf2 and $\mathrm{HO}-1$ expression in SH-SY5Y cells [40].

\section{Anthriscus nemorosa}

Anthriscus nemorosa (M. Beib.) Spreng. (chervil) is a common plant genus belonging to the family Apiaceae. Its EO contains caryophyllene (23.6\%), germacrene D (5.6\%), $\alpha$-terpineol (2.7\%), $\beta$-elemene (4.2\%), and trans-pinocarveol (9.8\%) as major constituents. The antimicrobial property of its EO has been reported [41]. The EO obtained from the aerial parts of $A$. nemorosa has been studied by Bagci et al. [42] for its beneficial effects on anxiety, depression, and cognition in scopolamine-induced amnesia model in rats. The rats were exposed to inhalation of $A$. nemorosa EO for $21 \mathrm{~d}$ and behavioral parameters were analyzed by $Y$-maze and radial armmaze tasks. Scopolamine $(0.7 \mathrm{mg} / \mathrm{kg}$ i.p.) was administrated 30 min prior the behavior testing. Also, anxiety- and depressionlike behaviors were tested in elevated plus-maze and forced swimming tests, respectively. Positive results were obtained for EOtreated groups in all behavioral tests, suggesting the benefits of A. nemorosa EO against cognitive defects, anxiety, and depression. Even though there was some behavioral evidence for memory improvement, more findings are required to elaborate the benefits of $A$. nemorosa in cognitive dysfunction.

\section{Salvia species}

The Salvia genus include around 900 species, of which Salvia officinalis L. (common sage/sage) and Salvia officinalis L. ssp. lavandulifolia (vahl) Gams (Spanish sage) of Lamiaceae family have prominent medicinal benefits [43]. The active constituents of S. officinalis EO are camphor (95.5\%), 1,8-cineole (59.0\%), cis-thujone (65.5\%), trans- thujone (40.1\%), $\alpha$-humulene (33.7\%), and linalool (35.0\%). S. lavandulifoila EO contains 1,8 cineole (34.5\%), $\alpha$ pinene (23.2\%), $\beta$-pinene (19.2\%), limonene (16.6\%), camphor (15.4\%), and $\beta$-caryophyllene (8.1\%) as main constituents [44]. In a single-blind randomized controlled trial led by Moss et al. [45], the reputed effects of these EOs on mood and cognition in healthy volunteers have been evaluated. S. officinalis EO-treated group showed better positive performance compared to control group. Results confirmed an enhancement in mood and cognitive performance deliberated through Bond-Lader mood scales and cognitive drug research system, respectively. EO of S. lavandulifolia does not exhibit any significant effects. EO of S. lavandulifolia and its constituents reported antioxidant [46], anti-inflammatory, oestrogenic [47], CNS depressant, and AChE inhibitory potential in bovine erythrocyte and human brain tissue [48] and in rat brain [49]. In a clinical trial conducted in healthy volunteers, EO treatment reported successive results on mood and cognition [50]. Oral administration of S. lavandulifolia EO in patients with mild/ 
moderate $A D$ reported significant improvement in memory and cognition in a pilot open-label study [51]. Even though S. lavandulifolia EO possesses antioxidant, anti-inflammatory, anti-AChE, and memory enhancement potential, it fails in a clinical study [45] and that might be due to lack of standardization and pharmacokinetics studies of this EO. The concentration of bioactive components varies in plants based on its region, climate, etc., and this variation remains a major drawback concerning the properties of $\mathrm{EO}$ and is likely to remain so.

\section{Melissa officinalis}

Melissa officinalis L. (lemon balm) of Labiatae has been used traditionally in nervous system diseases, cognitive dysfunction, and sedation [52]. Geranial (65.4\%), geranyl acetate (7.4), neral (24.7\%), (Z)-carveol (0.1\%), linalool (0.8\%), myrtenol (0.1\%), farnesene (0.1\%), 2,3-dehydro-1,8-cineole $(0.1 \%)$, and caryophyllene $(0.8 \%)$ are the active components that have been isolated from the leaves of $M$. officinalis EO [53]. Agitation is one of the main symptoms of $A D$. Aromatherapy of $M$. officinalis $E O$ or placebo (sunflower oil) in a double-blind placebo-controlled trial in $72 \mathrm{Alz}$ heimer's patients (agitation with severe dementia) has been reported by Ballard et al. [54] Patients were advised to apply oil combined with base lotion in faces and arms twice daily for $4 \mathrm{wk}$. Treatment analysis like Cohen-Mansfield Agitation Inventory score and quality of life indices were assessed and the results reflected $35 \%$ and $11 \%$ improvement in agitation in EO and placebo-treated groups, respectively. Later in 2011, a clinical trial report revealed that massaging EO in hands and upper arms of dementia patients with agitation does not produce any significant results compared to standard drug donepezil or placebo oil [55]. However, positive results of $M$. officinalis oil for its anti-agitation potential have also been reported $[56,57]$. While all these trials comprised comparatively short duration and small sample sizes, the significant improvement in agitation with $M$. officinalis oil appear to explain the importance for further long-term clinical studies, assessment of adverse effects, appropriate doses, and efficacy compared to standard drugs for AD.

\section{Juniperus communis}

Juniperus communis L. (juniper) belongs to the family Cupressaceae. The chemical compositions of its EO are $\alpha$-pinene (41.13\%), $\alpha$-thujene (3.78\%), myrcene (10.16\%), sabinene (11.73\%), $y$-terpinene (1.57\%), and limonene (8.63\%) followed by lower quantities of $\beta$-elemene (1.1\%), terpinen-4-ol (3.42\%), $\beta$-caryophyllene (1.03\%), eremophylene (1.17\%), and germacrene D (1.51\%). The EO obtained from needles and berries of J. communis has been reported to have carminative, diuretic, antianxiety, astringent, rubefacient, antispasmodic, stimulating, stomachic, blood purifier, antirheumatic, antiseptic, and tonic effects. $[58,59]$ Cioanco et al. [59] reported about the multiple exposure of juniper oil inhalation boosted memory defects in an $A \beta$ induced rat model of AD. In this study, rats were split up into 4 groups, of which control group received saline treatment $(0.9 \%$ $\mathrm{NaCl}$ ), disease group was subjected to ICV $A \beta(1-42)$ injection, and the other 2 treatment groups were subjected to inhalation of juniper volatile oil $1 \%$ and $3 \%$ for $20 \mathrm{~d}$ after ICV $A \beta(1-42)$ injection. Y-maze and radial arm maze tests were used for the evalua- tion of memory status. Juniper oil treated groups showed significantly less memory impairment in both behavioral tests as compared to $A \beta(1-42)$ alone treated group. Later Cioanco et al. [60] demonstrated that antioxidant and anti-AChE potential of juniper volatile oil ameliorates cognitive dysfunction in $A \beta(1-42)$-induced rat model of AD.

\section{Cocus nucifera}

Cocus nucifera L. (coconut) belonging to Arecaceae family, consists of saturated fatty acids (SFA) $92 \%$ and medium-chain fatty acids (MCFA) $62-70 \%$ as major constituents. MCFA can be transformed into ketone bodies, which are alternative energy source in the brain in conditions wherein disturbance in brain glucose level and can be favorable to humans progressing or earlier with cognitive dysfunction [61]. Hu Yang et al. [62] conducted a prospective study in Alzheimer's patients in which the test group was provided with coconut oil ( $40 \mathrm{~mL} /$ day) for $3 \mathrm{wk}$. The memory test such as lobo cognitive test and mini test scores pre- and postinvolvement were performed in test and control groups. A statistically appreciable elevation in test score was noticed in patients taking the oil and therefore a positive improvement in memory status was noted. An in vitro study conducted by Nafer et al. [63] highlighted the neuron protecting effects of coconut oil in $A \beta$-incited neurotoxicity in rat cortical neurons. Cells were initially induced with $A \beta$ for 1,6 , or $24 \mathrm{~h}$ and then treated with coconut oil further for $24 \mathrm{~h}$. Survival of neurons and various cellular parameters (synaptophysin labeling, cleaved caspase 3, and reactive oxygen species) were assessed. Reports unveiled that coconut oil protects against $A \beta$-induced neurotoxicity, inhibits $A \beta$-induced elevation of cellular stress markers, and in addition provides neuron protecting effects by activating Akt and ERK signaling pathways

\section{Pimpinella peregrina}

Pimpinella peregrina $\mathrm{L}$. is an aromatic herb belonging to Apiaceae family. The major constituents of its EO are trans-pinocarveol (35.1\%), $\alpha$-cubebene (12.4\%), pregeijerene (15.1\%), (+)-epi-bicyclosesquiphellandrene (7.5\%), and $\alpha$-terpineol $(6.7 \%)[64,65]$. EO is widely used in flavored drinks like raki, ouzo, pastis, arak etc. Adyn et al. [65] reported the effects of inhalation of EO from aerial parts of $P$. peregrina in scopolamine-induced memory deficits, depression, and anxiety in a rat model of AD. Rats were exposed to inhalation of EO (1\% and 3\%) continuously for $21 \mathrm{~d}$. Scopolamine was injected (i. p.) 30 min before the behavioral tests. Memory impairments were observed through radial arm-maze and Y-maze tests. Also, elevated plus-maze and forced swimming tests were used for checking anxiety and depressive behavior, respectively. Successive results were obtained in EO-treated groups as compared to respective scopolamine-treated groups, suggesting the neuroprotective effects of $P$. peregrine EO in the treatment of anxiety, depression, and memory deficits. In conclusion, more biochemical and histological findings are needed to prove the effect of $P$. peregrina EO on AD.

\section{Lavandula angustifolia}

Lavandula angustifolia Mill. (lavender) belongs to the family Lamiaceae. The dominant components of its EO are caryophyllene (24.12\%), terpinen-4-ol (9.57\%), $\beta$-phellandrene (16\%), and euca- 
lyptol (15.69\%) [66]. It has been used in the treatment of anxiety, migraines, stress, irritability, exhaustion, depression, headaches, digestion, colds, flatulence, insomnia, loss of appetite, stomach upset, liver diseases, nervousness, and aromatherapy $[67,68]$. Hritcu et al. [69] reported the effects of 2 distinct EOs from Lavandula hybrida Rev. and L. angustifolia subsp. angustifolia on neurological capability in scopolamine $(0.7 \mathrm{mg} / \mathrm{kg})$-induced amnesia model in rats. Lavender EO inhalation for 7 consecutive days notably hindered depression, anxiety and memory impairment in scopolamine treated rats as observed through various behavioural tests. A human study led by Moss et al. [70] unveiled that exposure of EOs of Rosmarinus officinalis L. and L. angustifolia significantly affects the mood and cognitive performances of sound volunteers. Aromatherapy of 4 different EOs from $R$. officinalis, Citrus limon (L.), Citrus sinensis (L.) Osbeck, and L. angustifolia reported significant improvement in cognitive function in a clinical trial led in 28 elderly people [71].

\section{R. officinalis}

Rosmarinis officinalis L. (rosemary) belongs to the family Lamiaceae. The EO of $R$. officinalis consist of $\alpha$-pinene (21.3\%), 1,8 cineole $(28.5 \%)$, camphor (27.7\%), camphene (8.7\%), $\beta$-pinene (4.7\%), and borneol (2.5\%) as major constituents. [72] Antioxidant, antiproliferative, antibacterial, antimutagenic, antiphlogistic, and chemopreventive, and ANS stimulant potentials of its EO has been reported $[73,74]$. Satiou et al. [75] have recently studied the beneficial effects of EO from leaves and flowers of $R$. officinalis on scopolamine-induced Alzheimer's-type dementia model in mice. The results showed that inhalation of $R$. officinalis EO $(4 \mu \mathrm{L} /$ $\mathrm{L}$ or $8 \mu \mathrm{L} / \mathrm{L}$ air) have shown a positive result in spontaneous alternation behavior in Y-maze test, and 1,8 cineole, $\alpha$-pinene, and $\beta$ pinene were found in dominant concentration in the mice brain. Asadi et al. [76] have tested the potential of EO from leaf and aerial part of $R$. officinalis on memory in aged and young mice. The test group were administered EO (200,400,600 and $800 \mathrm{mg} /$ $\mathrm{kg}$ i.p.) daily for $7 \mathrm{~d}$ and improvement in memory performances were found in all test groups. Filiptsora et al. [77] reported the effects of $R$. officinalis EO on the short-term and numerical memory in a study conducted in 79 school students (aged 13-17y). The result showed positive results as evidenced by increased image and number memory compared to control groups. The positive correlation of 1,8 cineole on mood and cognitive performances following inhalation of rosemary oil has been described in a clinical study conducted in healthy volunteers [78]. As mentioned above, $R$. officinalis EO reported memory enhancement potential in many clinical studies $[70,71]$. Further studies are essential for this oil to verify possibility for drug interactions and adverse effects in long duration trials and to determine appropriate dose that can mediate relevant neuroprotective effects.

\section{In vitro studies}

Ayaz et al. [79] reported the cholinesterase inhibitory activities and reactive oxygen species scavenging potential of EOs from the flowers and leaves of Persicaria hydropiper (L.) Delarbre. In AChE inhibition assay, EO of leaf exhibited $\mathrm{IC}_{50}$ of $120 \mu \mathrm{g} / \mathrm{mL}$ and flower of $220 \mu \mathrm{g} / \mathrm{mL}$, whereas flower and leaf EOs reported $I_{50}$ of 225 and $130 \mu \mathrm{g} / \mathrm{mL}$, respectively, in butyrylcholinesterase (BChE) inhibitory assay. In 1,1-diphenyl 2-picrylhydrazyl (DPPH) antiradicals assay, these EOs showed remarkable radical scavenging potentials. Also, $I C_{50}$ of 50 and $45 \mu \mathrm{g} / \mathrm{mL}$ for flower oil and 60 and $180 \mu \mathrm{g} / \mathrm{mL}$ for leaf oil was obtained in hydrogen peroxide and 2,2-azinobis3-ethylbenzthiazoline-6-sulfonic acid (ABTS) scavenging assays, respectively. Ahmed et al. [80] reported the antioxidant and anticholinesterase activities of EO from Rumex hastatus D. Don. It exhibited significant BChE and AChE inhibitory activities with $\mathrm{IC}_{50}$ of 97.38 and $32.54 \mu \mathrm{g} / \mathrm{mL}$, respectively. Also, $\mathrm{IC}_{50}$ values of 6.29 and $3.71 \mu \mathrm{g} / \mathrm{mL}$ were obtained for ABTS and DPPH assays, respectively. Salvia chionantha Boiss EO was analyzed for its antioxidant activity and reported $77.4 \pm 0.5 \%$ inhibition in ABTS assay. The anti-AChE and BChE activities were found to be $56.7 \pm 1.9 \%$ and $41.7 \pm 2.9 \%$, respectively [81]. In vitro anti-AChE activity of EO from Acorus calamus L. rhizomes has been studied and exhibited significant AChE inhibitory potential $\left(I_{50}=10.61 \mu \mathrm{g} / \mathrm{mL}\right)$ [82]. Ertas et al. [83] reported the anticholinesterase activities of EOs from Anchusa arvensis subsp. Orientalis (L.) Nordh. and Tragopogon latifolius Boiss. Both of them betrayed moderate AChE and BChE inhibitory activities.

EO isolated from leaf and stem of Gynura bicolor (Roxb.ex Willd.) DC. has been screened for anti-AChE activity. These oils have been evaluated and compared with standard AChE inhibitor pulegone. The leaf and stem oil inhibited AChE (53\%) at a concentration of $0.50 \mu \mathrm{g} / \mathrm{mL}$ with $\mathrm{ID}_{50}$ values of 85 and $92 \mu \mathrm{g} / \mathrm{mL}$, respectively. Both oils showed better results than pulegone [84]. EO obtained from fresh Chaerophyllum aromaticum L. root and aerial parts exhibited significant anticholinesterase and antioxidant activities [85]. Bonesi et al. [86] reported the cholinesterase inhibitory activities of EOs from Pinus nigra J. F. Arnold and Pinus heldreichii Christ. P. heldreichii was more active with $\mathrm{IC}_{50}$ of 80.6 and $51.1 \mu \mathrm{g} / \mathrm{mL}$ toward BChE and AChE inhibitory assays, respectively. EOs from Cistus libanotis L., Cistus salvifolius L., Cistus creticus L., Cistus villosus L., and Cistus monspeliensis L. were evaluated for antiradicals and anti-AChE activities. In ferric reducing antioxidant assay, C. libanotis exhibited most potent value of 19.2 I MFe (II)/g. In AChE inhibitory assay C. salvifolius revealed $\mathrm{IC}_{50}$ of $58.1 \mu \mathrm{g} / \mathrm{mL}$. Meanwhile, C. creticus, C. libanotis, and C. salvifolius exhibited significant anti-BChE effects with $\mathrm{IC}_{50}$ values of 29.1, 23.7, and $34.2 \mu \mathrm{g} / \mathrm{mL}$, respectively. In b-carotene bleaching test, $C$. monspeliensis EO exhibited better results with $\mathrm{IC}_{50}$ of $54.7 \mu \mathrm{g} / \mathrm{mL}$ [87]. Eminent results of all this data suggest the anticholinesterase and antioxidant potential of EOs for the development of therapeutic remedies targeting AD pathogenesis. - Table 2 shows the list of in vitro studies of EOs that possess antioxidant and anticholinesterase activities.

\section{Discussion}

This literature review displayed promising evidence that supports the use of EOs for reversing cognitive and memory impairment of $A D$. EOs obtained from numerous medicinal plants are reported to possess anti-AD potential. EOs of S. officinalis, S. officinalis ssp. lavandulifolia (vahl), M. officinalis, L. angustifolia, and $R$. officinalis have proven their putative effects in clinical studies. EOs are rich in various bioactive markers in different concentrations and it changes from place to place. Linalool, thymol, $\beta$-caryophyllene, 
- Table 2 List of in vitro studies of essential oils that possess antioxidant and anti-cholinesterase activities.

\begin{tabular}{|c|c|c|c|}
\hline Plant/source & Study design & Results & References \\
\hline P. hydropiper & AChE, BChE inhibition DPPH, ABTS, $\mathrm{H}_{2} \mathrm{O}_{2}$ assay & $\downarrow$ AChE, BChE, DPPH, ABTS, $\mathrm{H}_{2} \mathrm{O}_{2}$ activity & [79] \\
\hline R. hastatus & AChE, BChE inhibition DPPH, ABTS, $\mathrm{H}_{2} \mathrm{O}_{2}$ assays & $\downarrow$ AChE, BChE, DPPH, ABTS activity & {$[80]$} \\
\hline S. chionantha & $\begin{array}{l}\text { AChE, BChE inhibition } \\
\text { ABTS assays }\end{array}$ & $\downarrow$ AChE, BChE, ABTS activity & {$[81]$} \\
\hline A. calamus & AChE inhibition & $\downarrow$ AChE activity & {$[82]$} \\
\hline $\begin{array}{l}\text { A. arvensis subsp. Orientalis } \\
\text { T. latifolius }\end{array}$ & AChE, BChE inhibition & $\downarrow$ AChE, BChE activity & [83] \\
\hline G. bicolor & AChE inhibition & $\downarrow$ AChE activity & {$[84]$} \\
\hline C. aromaticum & $\begin{array}{l}\text { AChE inhibition } \\
\text { Antioxidant assay }\end{array}$ & $\begin{array}{l}\downarrow \text { AChE activity } \\
\text { Significant antioxidant activity }\end{array}$ & {$[85]$} \\
\hline $\begin{array}{l}\text { P. nigra } \\
\text { P. heldreichii }\end{array}$ & AChE, BChE inhibition & $\downarrow$ AChE, BChE activity & {$[86]$} \\
\hline $\begin{array}{l}\text { C. creticus } \\
\text { C. libanotis } \\
\text { C. salvifolius } \\
\text { C. monspeliensis } \\
\text { C. villosus }\end{array}$ & $\begin{array}{l}\text { AChE, BChE inhibition } \\
\text { FRAP assay, } \beta \text {-carotene bleaching assay }\end{array}$ & $\begin{array}{l}\downarrow \text { AChE, BChE acitivity } \\
\text { Significant antioxidant activity }\end{array}$ & [87] \\
\hline
\end{tabular}

carvacrol, $\alpha$-pinene, $\alpha$-terpineol, $\alpha$-terpinene, and eugenol are some of the components that are common in above-mentioned oils. - Fig. 1 depicts the chemical structure of some of the main constituents of EOs. Some are present in higher amount like linalool (60-70\%) in C. sativum, caryophyllene $(23.6 \%)$ in A. nemorosa, and 1,8 cineole $(46.0 \%)$ in $R$. officinalis while others are in minor amounts. Monoterpenes like pinene, limonene, sabinene, etc., are found to be responsible for the antioxidant and anticholinesterase properties [88]. Therefore, it seems to be important to screen the main constituents of EOs based upon the strength of the biologic potential and more findings are needed to establish the required dose and proportions that are necessary to protect the brain from degenerative diseases.

Majority of the clinical as well as animal studies prefer inhalation as the route of administration of EO for AD therapy. Aromatherapy for $A D$ are used since long back and found to be very effective. The aroma of EO acquired through inhaling or massaging directly affects mood and cognition. These oils are supposed to enter the blood stream through lung mucosa, nasal, or even diffuse directly into the olfactory nerve and reach limbic system in the brain [89]. The EOs mentioned in this review is mostly nontoxic at the recommended doses. Most of the EOs possess anticholinesterase property. In vitro studies of $15 \mathrm{EOs}$ that displayed both AChE and BChE inhibitory potentials are mentioned. ACh is the brain neurotransmitter involved in regulating memory and cognition and cholinesterase inhibitors prevent degradation of ACh and maintain its synaptic concentration. Hence, assessment of the potential shown by EOs on cholinesterase adds up a useful approach for developing new drugs for AChE/BChE inhibitor with fewer cholinergic side effects. Oxidative stress plays a major role in the pathophysiology of AD. Imbalance in oxidants/antioxidants defense generates free radical that causes cell/neuron damage.

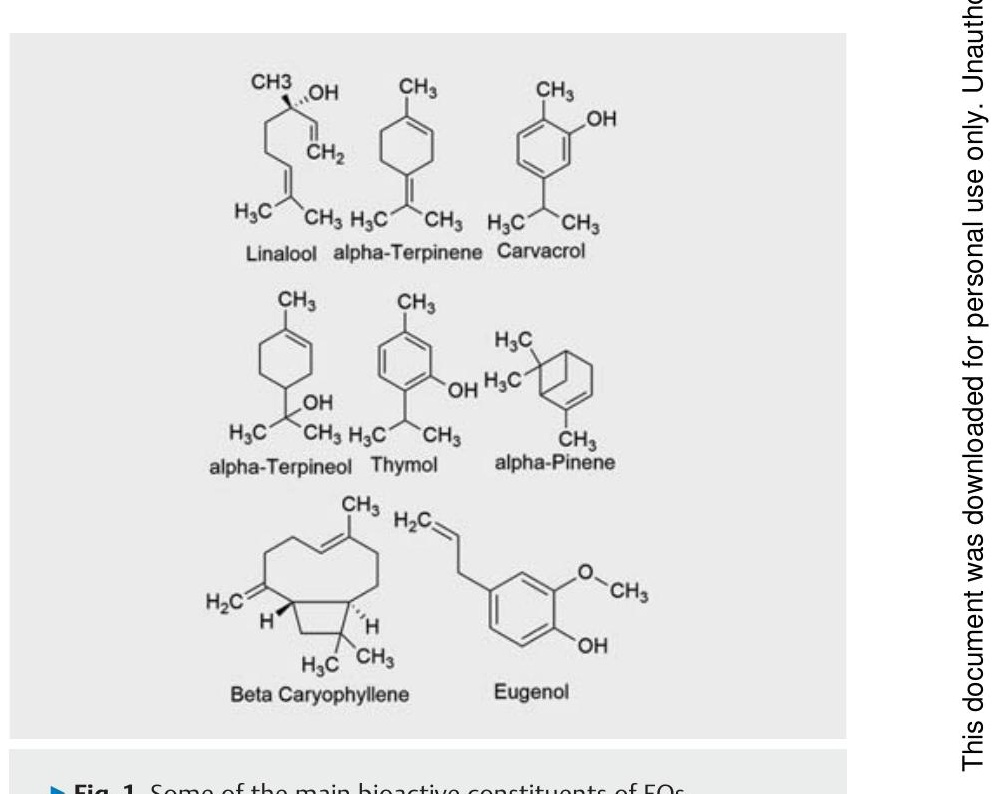

Fig. 1 Some of the main bioactive constituents of EOs.

Antioxidant-rich EOs can hence counteract the free radical mediated oxidative stress and thereby protects brain form neuronal damage. The ability of EOs to cross blood brain barrier remains as a main reason for activity in brain regions

However, it is important to initiate further studies on pharmacokinetics and toxicities of EOs and their bioactive markers responsible for anti-Alzheimer's action. More cell culture and in vivo studies are essential. All these findings result in the establishment of good interventions and subsequent development of safer and more effective anti-Alzheimer's drug. 
There are numerous natural resources with reputed ethnobotanical uses shown to ameliorate memory impairment in different Alzheimer's studies. However, comparatively only few are explored to determine any therapeutic support for their putative effects. Our literary survey revealed encouraging results regarding various EOs being studied in preclinical and clinical studies of $A D$ with significant effects in modulating the pathology through antiamyloid, antioxidants, anti-AChE, and memory enhancement activity. The literature studies disclosed many drugs that showed positive results in animal studies but failed in clinical trial. This demands more studies focused on human physiology, pharmacokinetics, dose, and route of administration. Thus, the establishment of potential targets and optimization of safety and efficacy of EOs in $A D$ remain as a promising area for future research.

Conflict of Interest

There are no conflicts of interest among the authors.

\section{References}

[1] Haass C, Selkoe DJ. Soluble protein oligomers in neurodegeneration: lessons from the Alzheimer's amyloid beta-peptide. Nat Rev Mol Cell Biol 2007; 8: 101-112

[2] Mohandas E, Rajmohan V, Raghunath B. Neurobiology of Alzheimer's disease. Indian J Psychiatry 2009; 51: 55-61

[3] Sanabria-Castro A, Alvarado-Echeverria I, Monge-Bonilla C. Molecular pathogenesis of Alzheimer's disease: an update. Ann Neurosci 2017; 24: $46-54$

[4] Dementia fact sheet № 362, 2015. Available at http://www.WHO.Int/ mediacentre/factsheets/fs362/en/. Accessed October 6, 2017

[5] Reitz C, Brayne C, Mayeux R. Epidemiology of Alzheimer's disease. Nat Rev Neurol 2011; 7: 137-152

[6] Kumar PS, Karthikeyan S, lyer PM, Namboori PK. Prediction of epigenetic variations in Alzheimer's disease identification of ethnic variants through pharmacogenomic approach. Res J Pharm Biol Chem Sci 2016; 7: 27422745

[7] Bertram L, Lill CM, Tanzi RE. The genetics of Alzheimer disease: back to the future. Neuron 2010; 68: 270-281

[8] Hang Y, Mucke L. Alzheimer mechanisms and therapeutic strategies. Cell 2012; 148: 1204-1222

[9] Tanzi RE. A brief history of Alzheimer's disease gene discovery. | Alzheimers Dis 2013; 33: S5-S13

[10] Giri M, Zhang M, Lu Y. Genes associated with Alzheimer's disease: an overview and current status. Clin Interv Aging 2016; 11: 665-681

[11] Rocchi A, Orsucci D, Tognoni G, Ceravolo R, Siciliano G. The role of vascular factors in late-onset sporadic Alzheimer's disease. Genetic and molecular aspects. Curr Alzheimer Res 2009; 6: 224-237

[12] Stefanova NA, Kolosova NG. Evolution of Alzheimer's disease pathogenesis conception. Moscow Univ Biol Sci Bull 2016; 71: 4-10

[13] Mohan CG, Gupta S. QSAR Models towards Cholinesterase Inhibitors for the Treatment of Alzheimer's Disease. In: Mohan CG, Gupta S. Oncology: Breakthroughs in Research and Practice. Hershey: IGI Global; 2017: 591636

[14] Roher AE, Kokjohn TA, Clarke SG, Sierks MR, Maarouf CL, Serrano GE, Sabbagh MS, Beach TG. APP/A $\beta$ structural diversity and Alzheimer's disease pathogenesis. Neurochem Int 2017; 12: 1-13

[15] Barage SH, Sonawane KD. Amyloid cascade hypothesis: pathogenesis and therapeutic strategies in Alzheimer's disease. Neuropeptides 2015; 52: $1-18$
[16] Konrath EL, Passos CD, Klein LC jr., Henriques AT. Alkaloids as a source of potential anticholinesterase inhibitors for the treatment of Alzheimer's disease. J Pharm Pharmacol 2013; 65: 1701-1725

[17] Fotiou D, Kaltsatou A, Tsiptsios D, Nakou M. Evaluation of the cholinergic hypothesis in Alzheimer's disease with neuropsychological methods. Aging Clin Exp Res 2015; 27: 727-733

[18] Craig LA, Hong NS, McDonald RJ. Revisiting the cholinergic hypothesis in the development of AD. Neurosci Biobehav Rev 2011; 35: 1397-1409

[19] Zhao Y, Zhao B. Oxidative stress and the pathogenesis of AD. Oxid Med Cell Longev 2013; 2013: 316523

[20] Wojtunik-Kulesza KA, Oniszczuk A, Oniszczuk T, Waksmundzka-Hajnos $M$. The influence of common free radicals and antioxidants on development of Alzheimer's disease. Biomed Pharmacother 2016; 78: 39-49

[21] Hong-Qi Y, Zhi-Kun S, Sheng-Di C. Current advances in the treatment of Alzheimer's disease: focused on considerations targeting $A \beta$ and tau. Transl Neurodegener 2012; 1: 21

[22] Alcolea-Palafox M, Posada-Moreno P, Ortuno-Soriano I, Pacheco-delCerro J, Martinez-Rincon C. Research Strategies developed for the Treatment of Alzheimer's Disease. Reversible and pseudo-irreversible Inhibitors of Acetylcholinesterase: Structure-activity Relationships and Drug Design. In: Atta-ur-Rahman, Choudhary MI, eds. Drug Design and Discovery in Alzheimer's Disease. Amsterdam: Elsevier; 2015: 426-477

[23] Mehta M, Adem A, Sabbagh M. New acetylcholinesterase inhibitors for Alzheimer's disease. Int ] Alzheimers Dis 2012; 2012: 728983

[24] Ayaz M, Sadiq A, Junaid M, Ullah F, Subhan F, Ahmed J. Neuroprotective and anti-aging potentials of essential oils from aromatic and medicinal plants. Front Aging Neurosci 2017; 9: 168

[25] Tongnuanchan P, Benjakul S. Essential oils: extraction, bioactivities and their uses for food preservation. J Food Sci Tech 2017; 79: R1231-R1249

[26] Edris AE. Pharmaceutical and therapeutic potentials of essential oils and their individual volatile constituents: a review. Phytother Res 2017; 21: 308-323

[27] Dobetsberger C, Buchbauer G. Actions of essential oils on the central nervous system: an updated review. Flavour Fragr 2011; 26: 300-316

[28] Bhalla Y, Gupta VK, Zaitak V. Anticancer activity of essential oils: a review. J Sci Food Agric 2013; 93: 3643-3653

[29] Cioanca O, Hritcu L, Mihasana M, Trifan A, Hancianu M. Inhalation of coriander volatile oil increased anxiolytic-antidepressant-like behaviors and decreased oxidative status in beta-amyloid (1-42) rat model of Alzheimer's disease. Physiol Behav 2014; 131: 68-74

[30] Mandal S, Manda M. Corriander (Corriandrum sativum L) essential oil: chemical and biological activity. Asian Pac J Trop Biomed 2015; 5: 421428

[31] Cioanca O, Hritcu L, Mihasana M, Hancianu M. Cognitive-enhancing and antioxidant activities of inhaled coriander volatile oil in amyloid $\beta(1-42)$ rat model of Alzheimer's disease. Physiol Behav 2013; 120: 193-202

[32] Mehta AK, Halder S, Khanna N, Tandon OP, Sharma KK. The effect of the essential oil of Eugenia caryophyllata in animal models of depression and locomotor activity. Nutr Neurosci 2013; 16: 233-238

[33] Kumar A, Aggrawal A, Pottabathini R, Singh A. Possible neuroprotective mechanisms of clove oil against icv-colchicine induced cognitive dysfunction. Pharmacol Report 2016; 68: 764-772

[34] Sajed H, Sahebkar A, Iranshahi M. Zataria multiflora Boiss. (Shirazi thyme) - an ancient condiment with modern pharmaceutical uses. J Ethnopharmacol 2013; 145: 686-698

[35] Majlessi N, Choopani S, Kamalinejad M, Azizi Z. Amelioration of amyloid $\beta$-induced cognitive deficits by Zataria multiflora Boiss. Essential oil in a rat model of Alzheimer's disease. CNS Neurosci Ther 2011; 18: 295-301

[36] Wei-Ping W, Juan L, Liang-Xiao Z, Ming-Yue Z, Yi-Zeng L. Chemical fingerprinting of Su-He-Xiang Wan and attribution of major characteristic peaks for its quality control by GC-MS. J Cent South Univ 2013; 20: 2115-2123 
[37] Koo BS, Lee SI, Ha JH, Lee DU. Inhibitory effects of the essential oil from SuHeXiang Wan on the central nervous system after inhalation. Biol Pharm Bull 2004; 27: 515-519

[38] Hong YK, Park SH, Lee S, Hwang S, Lee MJ, Kim D, Lee JH. Neuroprotective effect of SuHeXiang Wan in Drosophila models of Alzheimer's disease. J Ethnopharmacol 2011; 134: 1028-1032

[39] Park SH, Lee S, Hoong YK, Hwang S, Lee JH, Bang SM, Kim YK, Koo BS, Lee IS, Cho KS. Suppressive effects of SuHeXiang Wan on amyloid- $\beta 42$ induced extracellular signal-regulated kinase hyperactivation and glial cell proliferation in a transgenic Drosophila model of Alzheimer's disease. Biol Pharm Bull 2013; 36: 390-398

[40] Jeon S, Hur J, Jeong HJ, Koo BS, Pak SK. SuHeXiang Wan essential oil alleviates amyloid beta induced memory impairment through inhibition of tau protein phosphorylation in mice. Am J Chin Med 2011; 39: 917-932

[41] Pavlovic M, Petrovic S, Milenkovic M, Couladis M, Tzakou O, Niketic M. Chemical composition and antimicrobial activity of Anthriscus nemorosa root essential oil. Nat Prod Commun 2011; 6: 271-273

[42] Bagci E, Aydin E, Ungureanu E, Hritcu L. Anthriscus nemorosa essential oil inhalation prevents memory impairment, anxiety and depression in scopolamine-treated rats. Biomed Pharmacother 2016; 84: 1313-1320

[43] Miroddi M, Navarra M, Quattropani MC, Calapai F, Gangemi S, Calapai G. Systematic review of clinical trials assessing pharmacological properties of Salvia species on memory, cognitive impairment and Alzheimer's disease. CNS Neurosci Ther 2014; 20: 485-495

[44] Lopresti AL. Salvia (sage): a review of its potential cognitive-enhancing and protective effects. Drug R D 2017; 17: 53-64

[45] Moss L, Rouse M, Wesnes KA, Moss M. Differential effects of the aromas of Salvia species on memory and mood. Hum Psycho Pharmacol Clin Exp 2010; 25: 388-396

[46] Adam K, Sivropoulou A, Kokkini S, Lanaras T, Arsenakis M. Antifungal activities of Origanum vulgare subsp. Hirtum, Mentha spicata, Lavandula angustifolia and Salvia fruticosa essential oils against human pathogenic fungi. J Agric Food Chem 1998; 46: 1739-1749

[47] Perry NS, Houghton PJ, Sampson J, Theobald AE, Hart S, Lis-Balchin M. In-vitro activity of S. lavandulaefolia (Spanish sage) relevant to treatment of Alzheimer's disease. J Pharm Pharmacol 2011; 53: 1347-1356

[48] Perry NS, Houghton PJ, Theobald AE, Jenner P, Perry EK. In-vitro inhibition of erythrocyte acetylcholinesterase by Salvia lavandulaefolia essential oil and constituent terpenes. J Pharm Pharmacol 2000; 52: 895-902

[49] Perry NS, Houghton PJ, Jenner P, Keith A, Perry EK. Salvia lavandulaefolia essential oil inhibits cholinesterase in vivo. Phytomedicine 2002; 29: 48 51

[50] Tildesley NT, Kennedy DO, Perry EK, Ballard CG, Savelev S, Wesnes KA, Scholey AB. Salvia lavandulaefolia (Spanish Sage) enhances memory in healthy young volunteers. Pharmacol Biochem Behav 2003; 75: 669674

[51] Perry NS, Bollen C, Perry EK, Ballard C. Salvia for dementia therapy: review of pharmacological activity and pilot tolerability clinical trial. Pharmacol Biochem Behav 2013; 75: 651-659

[52] Ghaffariyan S, Mohammadi SA, Aharizad S. DNA isolation protocol for the medicinal plant lemon balm (Melissa officinalis, Lamiaceae). Genet Mol Res 2012; 11: 1049-1057

[53] Chung M]. Anti-diabetic effects of lemon balm (Melissa officinalis) essential oil on glucose and lipid-regulating enzymes in type 2 diabetic mice. $\mathrm{Br}$ J Nutr 2010; 104: 180-188

[54] Ballard CG, O’Brein JT, Reichelt K, Perry EK. Aromatherapy as a safe and effective treatment for the management of agitation in severe dementia: the results of a double-blind placebo-controlled trial with Melissa. J Clin Psychiatry 2002; 63: 553-558

[55] Burns A, Perry E, Holmes C, Francis P, Morris ], Howes M], Chazot P, Lees G, Ballard C. A double-blind placebo-controlled randomized trial of Melissa officinalis oil and donepezil for the treatment of agitation in Alzheimer's disease. Dement Geriatr Cogn Disord 2012; 31: 158-164
[56] Huang L, Abuhamdah S, Howes M], Elliot M, Ballard C, Holmes C. Pharmacological profile of essential oils derived from Lavandula angustifolia and Melissa officinalis with anti-agitation properties: focus on ligandgated channels. J Pharm Pharmacol 2008; 60: 1515-1522

[57] Elliott MS, Abuhamdah S, Howes MJR, Francis PT. The essential oils from Melissa officinalis L. and Lavandula angustifolia Mill as potential treatment for agitation in people with severe dementia. Int J Essent Oil Ther 2007; 1: 143-152

[58] Dahmane D, Dob T, Chelghoum C. Chemical composition of essential oils of Juniperus communis L. obtained by hydrodistillation and microwave-assisted hydrodistillation. J Matter Environ Sci 2015; 6: 1253-1259

[59] Cioanca O, Mircea C, Trifan A, Aprotosoaie AC, Hritcu L, Hancianu M. Improvement of amyloid- $\beta$-induced memory deficits by Juniperus communis L. Volatile oil in a rat model of Alzheimer's disease. Farmacia 2014; 62: 514-520

[60] Cioanca O, Hancianu M, Mihasan M, Hritcu L. Anti-acetylcholinesterase and antioxidant activities of inhaled juniper oil on amyloid beta (1-42)induced oxidative stress. Neurochem Res 2015; 40: 952-960

[61] Fernando WM, Martins I], Goozee KG, Brennan CS, Jayasena V, Martins $\mathrm{RN}$. The role of dietary coconut for the prevention and treatment of Alzheimer's disease: potential mechanisms of action. Br J Nutr 2015; 114 : $1-14$

[62] Hu Yang I, De la Rubia Orti JE, Selvi Sabater P, Sancho Castillo S, Rochina M], Manresa Ramon N, Montoya-Castillla I. [Coconut oil: nonalternative drug treatment against Alzheimer's disease]. Nutr Hosp 2015; 32: 2822-2827

[63] Nafar F, Clarke JP, Mearow KM. Coconut oil protects cortical neurons from amyloid beta toxicity by enhancing signaling of cell survival pathways. Neurochem Int 2017; 105: 64-79

[64] Tabanca N, Demirci B, Kirimer N, Baser KH, Bedir E, Khan IA, Wedge DE. Gas chromatographic-mass spectrometric analysis of essential oils from Pimpinella aurea, Pimpinella corymbosa, Pimpinella peregrina and Pimpinella puberula gathered from Eastern and Southern Turkey. J Chromatogr A 2005; 1097: 192-198

[65] Aydin E, Hritcu L, Dogan G, Hayta S, Bagci E. The effects of inhaled Pimpinella peregrina essential oil on scopolamine-induced memory impairment, anxiety, and depression in laboratory rats. Mol Neurobiol 2016; 53: 6557-6567

[66] Jianu C, Pop G, Gruia AT, Horhat FG. Chemical composition and antimicrobial activity of essential oils of lavender (Lavandula angustifolia) and lavandin (Lavandula $x$ intermedia) grown in Western Romania. Int J Agric Biol 2013; 15: 772-776

[67] Hui L, He L, Huan L, XiaoLan L, AiGuo Z. Chemical composition of lavender essential oil and its antioxidant activity and inhibition against rhinitis related bacteria. Afr J Microbiol Res 2010; 4: 309-313

[68] Lin PW, Chan WC, Ng BF, Lam LC. Efficacy of aromatherapy (Lavandula angustifolia) as an intervention for agitated behaviors in Chinese older persons with dementia: a cross-over randomized trial. Int J Geriatr Psychiatry 2007; 22: 405-410

[69] Hritcu L, Cioanca O, Hancianu M. Effect of lavender oil inhalation on improving scopolamine-induced spatial memory impairment in laboratory rats. Phytomedicine 2012; 19: 529-534

[70] Moss M, Cook J, Wesnes K, Duckett P. Aromas of rosemary and lavender essential oils differentially affect cognition and mood in healthy adults. Int J Neurosci 2003; 113: 15-38

[71] Jimbo D, Kimura V, Taniguchi M, Inour M, Urakami K. Effect of aromatherapy on patients with Alzheimer's disease. Psychogeriatrics 2009; 9: 173-179

[72] Takayama C, de-Faria FM, de Almeida ACA, Dunder RJ, Manzo LP, Socca EAR. Chemical composition of Rosmarinus officinalis essential oil and antioxidant action against gastric damage induced by absolute ethanol in the rat. Asian Pac J Trop Biomed 2016; 6: 677-681 
[73] Sayorwan W, Ruangrungsi N, Piriyapunyporn T, Hongratanaworakit T, Naiphinich Kotchabhakdi N, Siripornpanich V. Effects of inhaled rosemary oil on subjective feelings and activities of the nervous system. Sci Pharm 2013; 81: 531-542

[74] Stefanovits-Banyai E, Tulok MH, Hegedus A, Renner C, Varga IS. Antioxidant effect of various rosemary (Rosmarinus officinalis L.) clones. Acta Biologica Szegediensis 2003; 47: 111-113

[75] Satou T, Hanashima Y, Mizutani I, Koike K. The effect of inhalation of essential oil from Rosmarinus officinalis on scopolamine-induced Alzheimer's type dementia model in mice. Flavour Fragr J 2017; 33: 1-5

[76] Asadi F, Farahani FK. Effect of essential oil of leaf and aerial part of Rosmarinus Officinalis on passive avoidance memory in aged and young mice. J Alzheimers Dis Parkinsonism 2017; 7 (Suppl.): 6

[77] Filiptsova OV, Gazzavi-Rogozina LV, Timoshyna IA, Naboka OI, Dyomina Ye V, Ochkur AV. The effect of the essential oils of lavender and rosemary on the human short-term memory. Alexandria J Med 2018; 54 : 41-44

[78] Moss M, Oliver L. Plasma 1, 8-cineole correlates with cognitive performance following exposure to rosemary essential oil aroma. Ther Adv Psychopharmacol 2012; 2: 103-113

[79] Ayaz M, Junaid M, Ullah F, Sadiq A, Khan MA, Ahmad W. Comparative chemical profiling, cholinesterase inhibitions and antiradicals properties of essential oils from Polygonum hydropiper L: a preliminary anti-Alzheimer's study. Lipids Health Dis 2015; 14: 141

[80] Ahmad S, Ullah F, Sadiq A, Ayaz M, Imran M, Ali M. Chemical composition, antioxidant and anticholinesterase potentials of essential oil of Rumex hastatus $D$. Don collected from the North West of Pakistan. Complement Altern Med 2016; 16: 29

[81] Tel G, Ozturk M, Duru ME, Harmandar M, Topcu G. Chemical composition of the essential oil and hexane extract of Salvia chionantha and their antioxidant and anticholinesterase activities. Food Chem Toxicol 2010; 48: 3189-3193

[82] Mukherjee PK, Kumar V, Mal M, Houghton PJ. In vitro acetylcholinesterase inhibitory activity of the essential oil from Acorus calamus and its main constituents. Planta Med 2010; 73: 283-285

[83] Erta A, Goern AC, Boga M, Yesil Y, Kolak U. Essential oil compositions and anticholinesterase activities of two edible plants Tragopogon latifolius var. angustifolius and Lycopsis orientalis. Nat Prod Res 2014; 28: 14051408

[84] Miyazaw M, Nakahashi H, Usami A, Matsuda N. Chemical composition, aroma evaluation, and inhibitory activity towards acetylcholinesterase of essential oils from Gynura bicolor DC. J Nat Med 2010; 70: 282-289

[85] Petrovic GM, Stamenkovic JG, Kostevskia IR, Stojanovica GS, Mitica VD, Zlatkovic BK. Chemical composition of volatiles; antimicrobial, antioxidant and cholinesterase inhibitory activity of Chaerophyllum aromaticum L. (Apiaceae) essential oils and extracts. Chem Biodivers 2017. doi:10.1002/cbdv.201600367

[86] Bonesi M, Menichini F, Tundis R, Loizzo MR, Conforti F, Passalacqua NG, Statti GA, Menichini F. Acetylcholinesterase and butyrylcholinesterase inhibitory activity of Pinus species essential oils and their constituents. J Enzyme Inhib Med Chem 2010; 25: 622-628

[87] Loizzo MR, Jemia MB, Senatore F, Bruno M, Menichini F, Tundis R. Chemistry and functional properties in prevention of neurodegenerative disorders of five Cistus species essential oils. Food Chem Toxicol 2013; 259: 586-594

[88] Aazza S, Lyoussi B, Miguel MG. Antioxidant and anti-acetylcholinesterase activities of some commercial essential oils and their major compounds. Molecules 2011; 16: 7672-7690

[89] Ali B, Al-Wabel NA, Shams S, Ahamad A, Alam Khan S, Anwar F. Essential oils used in aromatherapy: A systematic review. Asian Pacific J Trop Biomed 2015; 5: 601-611 